\title{
Efeito do Fósforo e do Potássio sobre o Desenvolvimento e a Nodulação de Três Leguminosas Anuais de Estação Fria ${ }^{1}$
}

\author{
Rodrigo Holz Krolow², Claudio Mistura ${ }^{3}$, Rogério Waltrick Coelho ${ }^{4}$, Lotar Siewerdt ${ }^{5}$, \\ Élio Paulo Zonta ${ }^{6}$
}

\begin{abstract}
RESUMO - Este experimento foi conduzido em casa de vegetação da Embrapa Clima Temperado, Pelotas, RS, com o objetivo de avaliar os efeitos de diferentes doses de fósforo e potássio na produção de matéria seca da parte aérea e das raízes, comprimento da parte aérea e sistema radicular, escore e eficiência da nodulação de três leguminosas forrageiras anuais de estação fria. Os tratamentos consistiram de cinco doses de $\mathrm{P}\left(0,0 ; 1,08 ; 2,15 ; 3,23\right.$ e $4,30 \mathrm{mg} / \mathrm{dm}^{3}$ de $\left.\mathrm{P}_{2} \mathrm{O}_{5}\right)$ e $\mathrm{K}\left(0,0 ; 0,43 ; 0,85 ; 1,28\right.$ e $1,70 \mathrm{mg} / \mathrm{dm}^{3}$ de $\left.\mathrm{K}_{2} \mathrm{O}\right)$, correspondendo a 0,0 (controle) 1, 2, 3 e 4 vezes a recomendação da análise de solo, em vasos, com 8 kg de solo tipo Planossolo, unidade de mapeamento Pelotas. As leguminosas utilizadas foram: Trifolium resupinatum L. cv. Kyambro (trevo-persa), Trifolium subterraneum L. cv. Woogenellup e Lotus subbiflorus Lag. cv. El Rincón. O delineamento experimental foi o completamente ao acaso, em arranjo fatorial 3 x 5 x 5, com três repetições. O trabalho foi conduzido no período de maio a outubro de 2000, sendo os dados colhidos ao final do período experimental, aproximadamente 170 dias após a semeadura. A maioria das características estudadas não foi influenciada pela aplicação de potássio, e sim pela aplicação de fósforo. Para as variáveis relacionadas com produção (MS parte aérea e raízes), o trevo-persa foi a espécie mais produtiva. Para a nodulação, o trevo-subterrâneo e o Lotus El Rincón apresentaram maior eficiência e quantidade de nódulos.
\end{abstract}

Palavras-chave: adubação, lotus El Rincón, trevo-persa, trevo-subterrâneo

\section{Effect of Phosphorus and Potassium on Development and Nodulation of Three Cool Season Annual Legumes}

\begin{abstract}
This experiment was established in greenhouse at Embrapa Clima Temperado, Pelotas, RS, with the objective to evaluate the effects of different doses of phosphorus and potassium on dry matter production of aerial biomass and roots, length of above ground parts and roots and efficiency and score of nodulation of three cool season annual forage legumes. The treatments were five doses of P $\left(0,0 ; 1,08 ; 2,15 ; 3,23\right.$ e 4,30 mg de $\left.\mathrm{P}_{2} \mathrm{O}_{5} / \mathrm{dm}^{3}\right)$ and $\mathrm{K}\left(00,0 ; 0,43 ; 0,85 ; 1,28\right.$ e $1,70 \mathrm{mg} \mathrm{de} \mathrm{K}_{2} \mathrm{O} / \mathrm{dm}^{3}$ ) representing to 0,0 (control ) and 1, 2, 3 and 4 times the soil analysis recommendation, in pots, filled up with $8 \mathrm{~kg}$ de soil type Planossolo, mapping unit Pelotas. The legumes used were: Trifolium resupinatum L. cv. Kyambro (persian clover), Trifolium subterraneum L. cv. Woogenellup and Lotus subbiflorus Lag. cv. El Rincón. The experimental design consisted of a 5x5x3 factorial treatment arrangement, in a completely randomized design, with three replications. The experiment was carried out from May to October 2000, and the data were collected at the end of the experimental period, approximately 170 days after sowing. The majority of variables were not affected by K, but by P fertilization. For the variables related with production, persian clover was the most productive species. For nodulation, subterranean clover and Lotus El Rincón showed higher nodule numbers and efficiency.
\end{abstract}

Key Words: fertilization, lotus El Rincón, persian clover, subterranean clover

\section{Introdução}

As áreas de terras baixas no Estado do Rio Grande do Sul, são destinadas basicamente ao cultivo do arroz irrigado (Oryza sativa L.), sendo comum a permanência dessas áreas em pousio após a lavoura. A prática de um cultivo único favorece o surgimento de desequilíbrios nutricionais, diminuição da matéria orgânica do solo e proliferação de doenças, pragas e invasoras (Potter,1986), evidenciando a necessidade de rotação de culturas. A dificuldade de cultivo com plantas anuais sensíveis ao excesso de água leva a um sub-aproveitamento das áreas e, como alternativa de uso mais intensivo, Bauer (1984), Gomes et al. (1993) e Rocha et al. (2003) apontam o estabelecimento de pastagens, principalmente com espécies leguminosas.

\footnotetext{
1 Parte da dissertação de mestrado do primeiro autor, financiado pela EMBRAPA/UFPEL.

2 Eng.-Agr., M.Sc. Rua Ramiro Barcelos 2111/Ap.03, CEP: 90035-007 Porto Alegre, RS. E.mail: rhk@ufpel.tche.br

3 Eng.-Agr., D.Sc., Pós-Doutorando no DTCS-UNEB - Juazeiro, BA. E.mail: cmistura@ig.com.br

4 Eng.-Agr., Ph.D., Embrapa - Clima Temperado. Caixa Postal 403, CEP: 96001-970 Pelotas, RS. E.mail:rwcoelho@cpact.embrapa.br

5 Eng.-Agr., Ph.D., Prof. do Dep. de Zootecnia - UFPEL. E.mail: lotar@ufpel.tche.br

6 Eng.-Agr., Prof. Adjunto, Dept. Matemática, Estatística e Computação - IFM/UFPel
} 
Todavia, para promover a integração lavoura x pastagens, as forrageiras a serem introduzidas devem ser adaptáveis às condições edafoclimáticas do local, compatíveis de coexistir e passíveis de um mesmo manejo (Abramides,1986).

Para obtenção de forragem de melhor qualidade e maior quantidade no período crítico (outono-inverno), com a introdução de espécies de estação fria, a adubação é indispensável, pois aumenta o fornecimento de nutrientes, uma vez que a fertilidade natural dos solos é baixa. A fertilidade e as práticas de adubação têm profunda influência sobre a quantidade e a qualidade das forrageiras, podendo influenciar a concentração de nutrientes na forragem, assim como seu consumo pelos animais (Correia, 1983).

O crescimento das plantas se realiza, fundamentalmente, pela transformação do dióxido de carbono existente no ar e da água do solo em hidratos de carbono por meio da fotossíntese, utilizando a energia solar. Os nutrientes minerais, além de participarem dos processos metabólicos de assimilação, passam a fazer parte dos compostos orgânicos essenciais para o crescimento das forrageiras, em quantidades variáveis segundo a espécie vegetal.

O fósforo é um dos nutrientes essenciais para as plantas. Malavolta et al. (1974) consideram o fósforo o mais importante elemento para as pastagens, após o nitrogênio; esse nutriente desempenha papel principal nos períodos iniciais da vida das plantas, quando estas necessitam de elevada disponibilidade no solo. É essencial para o desenvolvimento radicular e perfilhamento, passando a sua deficiência a limitar a capacidade produtiva das pastagens (Guss et al., 1990, Moreira et al., 2002). A carência de fósforo manifesta-se pelo ciclo vegetativo curto, pela falta ou pelo desenvolvimento deficiente de hastes em gramíneas forrageiras, pela presença de invasoras típicas de solos pobres e pela ausência de leguminosas.

Segundo Sheard et al. (1971), a fertilização com fósforo tem diminuído falhas de estabelecimento. Esses autores observaram, em casa de vegetação, que a adubação na semeadura da alfafa (Medicago sativa L.) provocou estabelecimento mais rápido, o que é muito importante quando novas espécies foram introduzidas. Kornelius (1972) observou aumento significativo na produção de matéria seca desta espécie, em seis tipos de solos.

Stammel (1968) constatou que a aplicação de fósforo proporcionou aumento altamente significativo na produção de matéria seca do trevo-vermelho
(Trifolium pratense L.). Segundo Jones et al. (1977), a adubação fosfatada também influenciou a nodulação da soja (Glycine max (L.) Merr.) e fez com que aumentasse o número de nódulos por planta e o tamanho dos nódulos. Estudos de Jones \& Freitas (1970) com quatro leguminosas tropicais mostraram que todas responderam ao fósforo, com aumento de produção. Bailey \& Laidlan (1998) obtiveram, em casa-de-vegetação, incremento de produção de matéria seca e peso de raízes, com doses crescentes de $\mathrm{P}$ e K em trevo-branco (Trifolium repens L.).

O potássio é, após o nitrogênio, o nutriente exigido pelas plantas em maior quantidade. Sua influência na produtividade de espécies ou cultivares varia com o requerimento do nutriente para o crescimento da planta e a habilidade das plantas em extraí-lo do solo e da fertilização fosfatada (Crowder \& Chheda, 1982). Na produção de forrageiras para corte, fenação ou ensilagem, é necessária especial atenção à adubação potássica, pois é um dos nutrientes extraídos do solo em maiores quantidades através da forragem colhida (Oliveira, 1995).

Segundo Werner (1984), para as leguminosas, a deficiência do potássio, além de afetar o crescimento da planta, diminui a nodulação (número e tamanho dos nódulos), afetando a fixação de nitrogênio. Sintomas de deficiência são bastante comuns quando em consorciação, em razão da menor capacidade das leguminosas em extrair este nutriente do solo. Em pastos consorciados, quando os teores estão abaixo de 1,0\% na parte aérea da planta, há limitação de crescimento, causando diminuição da produção de massa verde, e diminuição da leguminosa na pastagem, o que é limitante para o melhoramento da composição botânica (Werner et al., 1983). A deficiência do nutriente nas plantas afeta tanto seu crescimento vegetativo como o desenvolvimento dos tecidos e órgãos de armazenamento. Em quantidades adequadas, aumenta a longevidade das plantas e sua tolerância às baixas temperaturas (Honda \& Honda,1990). Rhykerd \& Overdahl (1972) relatam que é necessário elevado nível de potássio no solo para assegurar adequado suprimento às plantas sob baixas temperaturas.

Monteiro et al. (1980) estudaram o efeito da adubação potássica em cinco leguminosas forrageiras tropicais e observaram aumentos na produção de matéria seca e na proteína total por área. Honda \& Honda (1990) determinaram que o potássio é o fertilizante chave para o rendimento elevado e a alta qualidade da alfafa.

R. Bras. Zootec., v.33, n.6, p.2223-2230, 2004 (Supl. 3) 
Na região sul, observa-se que são escassas as informações sobre manejo da adubação fosfatada e potássica em leguminosas como trevo-persa (Trifolium resupinatum L. cv. Kyambro), trevosubterrâneo (Trifolium subterraneum L. cv. Woogenellup) e Lotus El Rincón (Lotus subbiflorus Lag. cv. El Rincón), o que proporciona, às vezes, implantação incorreta. Diante desse fato, e em razão de o fósforo e o potássio serem importantes nutrientes para as plantas, desenvolveu-se este trabalho com o objetivo de avaliar os efeitos das adubações fosfatada e potássica sobre três leguminosas de estação fria.

\section{Material e Métodos}

O experimento foi conduzido em casa de vegetação pertencente ao Centro de Pesquisas Agropecuárias de Clima Temperado, EMBRAPA, localizado no município de Capão do Leão, RS, na região fisiográfica denominada Litoral Sul.

O solo utilizado, classificado como Planossolo, da unidade de mapeamento Pelotas (Brasil,1973), foi colhido até a profundidade de $20 \mathrm{~cm}$, passado em peneira com malha de $5 \mathrm{~mm}$ de abertura, para remoção de cascalhos e fragmentos de raízes, e, posteriormente secado ao ar. A análise química mostrou os seguintes resultados: pH (em água, relação 1:2,5) = 4,2; P (Mehlich-1) = 9,6 mg/L; K = 95,75 mg/L; $\mathrm{Ca}=1,08$ cmolc; $\mathrm{Mg}=0,87$ cmolc $; \mathrm{Al}=1,9$ cmolc e $\mathrm{MO}=3,88 \%$.

Foram utilizados baldes plásticos de 10 litros, contendo $8 \mathrm{~kg}$ de solo. Realizou-se a calagem, de acordo com a recomendação do método SMP (Shoemaker, Mclean \& Pratt), $\left(50 \mathrm{mg} / \mathrm{dm}^{3}\right.$ de calcário dolomítico faixa C), 60 dias antes da semeadura. A classificação textural do solo foi classe 4 (11 a 25\% de argila).

O delineamento experimental utilizado foi o completamente ao acaso para o estudo de 75 tratamentos resultantes do arranjo fatorial 3 x 5 x 5 (espécies $\mathrm{x}$ doses de $\mathrm{P}$ x doses de K), com três repetições. As espécies estudadas foram: trevo-subterrâneo (Trifolium subterraneum L. cv. Woogenellup), trevo-persa (Trifolium resupinatum L. cv. Kyambro) e Lotus El Rincón (Lotus subbiflorus Lag. cv. El Rincón). As sementes foram escarificadas e inoculadas com inoculantes biológicos específicos.

Os tratamentos consistiram de cinco doses de $\mathrm{P}$ $\left(0,0 ; 1,08 ; 2,15 ; 3,23\right.$ e 4,30 mg/dm ${ }^{3}$ de $\left._{2} \mathrm{O}_{5}\right)$ e K $(0,0$;
0,43; 0,85; 1,28 e $1,70 \mathrm{mg} / \mathrm{dm}^{3} \mathrm{de}_{2} \mathrm{O}$ ), correspondentes a $0,1,2$, 3 e 4 vezes, respectivamente, a recomendação de $\mathrm{P}_{2} \mathrm{O}_{5}$ e $\mathrm{K}_{2} \mathrm{O}$ pela análise do solo, de acordo com a Comissão de Fertilidade do Solo-RS/SC (1994). Todos os vasos receberam adubação com micronutrientes $\left(0,5 \mathrm{mg} / \mathrm{dm}^{3}\right)$. Fósforo, K e micronutrientes foram misturados ao solo na forma de superfosfato triplo, cloreto de potássio e FTE BR 12 , respectivamente, antes do solo ser acondicionado nos vasos.

A semeadura ocorreu em 05 de maio de 2000, usando-se 10-12 sementes/vaso. Após uma semana da emergência, efetuou-se o desbaste nos vasos, deixando-se quatro plantas por vaso. Durante o período experimental, adicionou-se, diariamente, água destilada para ajustar o nível de umidade dos solos, mantido sempre próximo à capacidade de campo. A cada 15 dias, todos os vasos eram rotacionados aleatoriamente.

Em 18 de agosto de 2000, as plantas de cada tratamento foram colhidas a $5 \mathrm{~cm}$ do solo. A partir de 23 de outubro de 2000, iniciou-se a avaliação final do experimento. As plantas de cada tratamento foram novamente colhidas para determinação da produção de MS da parte aérea por vaso. Após a colheita, as amostras foram acondicionadas em sacos de papel e levadas à estufa de ar forçado, para secagem até peso constante $\left(72\right.$ horas, a $\left.65^{\circ} \mathrm{C}\right)$. As raízes foram separadas da terra, por lavagem em água corrente sobre peneira de $0,5 \mathrm{~mm}$. Foi utilizado o mesmo procedimento adotado na MS da parte aérea para a obtenção da produção de MS das raízes por vaso. A produção total de MS da parte aérea por vaso foi obtida pela soma dos valores encontrados nos cortes realizados entre 18/08/00 e 23/10/00.

Mediu-se o comprimento da parte aérea com uma régua graduada em $\mathrm{cm}$, da base da planta até a ponta da última folha. O sistema radicular, da base da planta até sua extremidade, foi medido da mesma maneira. Para quantificação da nodulação foram atribuídos escores de 1 a 5 , com base na quantidade de nódulos no sistema radicular. O escore 1 foi atribuído às raízes que apresentaram de 1-10 nódulos/raiz; escore 2 (10-20 nódulos); escore 3 (20-30 nódulos); escore 4 (30-40 nódulos); escore 5 (mais de 40 nódulos). A avaliação da eficiência dos nódulos também foi efetuada atribuindo-se às raízes escores de $1 \mathrm{a} 4$, pelo exame da nodulação existente, com base em sua coloração, tamanho e localização no sistema radicular. Escore 1: nódulos ineficientes, pequenos, a maioria 
localizada nas raízes secundárias; escore 2: maioria dos nódulos ineficientes, alguns poucos eficientes, pequenos e médios, localizados nas raízes secundárias e/ou próximos à raíz principal; escore 3: maioria dos nódulos eficientes, alguns poucos ineficientes, grandes, médios e/ou pequenos, localizados na raíz principal, próximos à raíz principal e/ou raízes secundárias; escore 4: nódulos eficientes, grandes, a maioria localizada na raíz principal e proximidades. A metodologia aplicada foi a de Sampaio (1988).

Os dados foram analisados por análises de variância e de regressão polinomial, utilizando-se o programa SANEST (Zonta \& Machado, 1984).

\section{Resultados e Discussão}

As médias de produção de MS da parte aérea e das raízes, comprimento da parte aérea, escore e eficiência de nodulação das espécies, em todos os tratamentos, são apresentadas na Tabela 1.

A maior produção de MS da parte aérea da raiz e comprimento da parte aérea ocorreu no trevo-persa (73,74 e 28,57 g/vaso e $93,88 \mathrm{~cm}$, respectivamente). O trevo-subterrâneo foi superior ao Lotus El Rincon na MS da parte aérea e raiz, mas inferior no comprimento da parte aérea. Na eficiência de nodulação o trevo-subterrâneo foi superior aos demais. As espécies responderam positivamente ao aumento na dose de adubo fosfatado (Figura 1).

Para o trevo-persa, a maior média original da produção de MS da parte aérea (85,53 g/vaso) ocorreu na dose quatro vezes a recomendada pela análise de solo, corroborando os resultados apresentados por Lopes \& Monks (1985), que observaram aumento na produção de forragem desta espécie, em um
Planossolo, com níveis crescentes de fósforo. A dose estimada de máxima eficiência biológica na produção de MS foi 3,8 vezes a recomendada.

No trevo-subterrâneo, a maior produção de MS da parte aérea (72,13 g/vaso) foi obtida com a dose três vezes a recomendada. Carâmbula \& Durán (1964) constataram resposta marcante do trevosubterrâneo à aplicação de fertilizantes fosfatados, em condições semelhantes às deste experimento. Morón \& Risso (2001) obtiveram a maior produção de MS do trevo-branco (Trifolium repens L.) na maior dose de fósforo aplicada. Estas constatações salientam a importância da adubação fosfatada para boa produção de forragem nas leguminosas de estação fria. No presente estudo, a dose estimada que proporcionou a máxima produção de MS no trevo subterrâneo foi 3,10 vezes a recomendada.

A dose três vezes a recomendada também proporcionou a maior produção de MS da parte aérea (45,16 g/vaso) no Lotus El Rincón, em máxima eficiência biológica (3,06 vezes a dose recomendada). Os resultados coincidem com os obtidos por Risso (1990), que observou aumentos na produção de MS do Lotus El Rincón com as doses de P. Marchezan et al. (2002), pesquisando níveis de adubação (0,5; 1,0 e 1,5 vezes a recomendação de adubação para RS e SC) para forrageiras de estação fria, constaram na dose recomendada (nível 1) maior produção de foragem para a leguminosa consorciada com azevém em área de várzea.

Na Figura 2, observa-se o efeito das doses de fósforo nas médias das três espécies. A maior produção de MS das raízes foi obtida com a dose 1,08 vezes a recomendada (20,72 g/vaso), com a máxima eficiência da adubação fosfatada verificada

Tabela 1 - Produção de MS da parte aérea (PA) e das raízes (R), comprimento (COMP) da parte aérea, escore e eficiência da nodulação do Lotus El Rincón (R), trevo-persa (TP) e trevo-subterrâneo (TS)

Table 1 - Date of DM production of aerial biomass $(A B)$ and roots $(R)$, length $(L)$ of above ground parts, efficiency and score of nodulation on Lotus El Rincón (R), persian clover (PC) and subterranean clover (SC)

\begin{tabular}{|c|c|c|c|c|c|}
\hline $\begin{array}{l}\text { Espécies } \\
\text { Species }\end{array}$ & $\begin{array}{c}\text { MS-PA (g/vaso) } \\
D M-A B(g / p o t)\end{array}$ & $\begin{array}{c}\text { MS-R (g/vaso) } \\
D M-R(g / p o t)\end{array}$ & $\begin{array}{c}\text { COMP-PA }(\mathrm{cm}) \\
L\end{array}$ & $\begin{array}{c}\text { Escore (1-5) } \\
\text { Score }\end{array}$ & $\begin{array}{c}\text { Eficiência (1-4) } \\
\text { Efficiency }\end{array}$ \\
\hline $\mathrm{R}$ & $39,36 c$ & $12,10 \mathrm{c}$ & $87,20 \mathrm{~b}$ & $2,81 \mathrm{a}$ & $2,09 \mathrm{~b}$ \\
\hline TP & $73,74 a$ & $28,57 \mathrm{a}$ & $93,88 \mathrm{a}$ & $2,35 b$ & $1,99 \mathrm{~b}]$ \\
\hline$P C$ & & & & & \\
\hline TS & $62,27 b$ & $16,64 b$ & $44,47 c$ & $2,75 \mathrm{a}$ & $2,63 \mathrm{a}$ \\
\hline
\end{tabular}

Médias seguidas da mesma letra, na coluna, não diferem entre si pelo teste de Duncan (5\%).

Means followed by same letter, in the column, are not diferent by Duncan test (5\%).

R. Bras. Zootec., v.33, n.6, p.2223-2230, 2004 (Supl. 3) 
com a dosagem 1,27 vezes a recomendação. A equação cúbica, apesar de não representar bem um processo biológico, foi a escolhida por apresentar o melhor $\mathrm{R}^{2}$ e, portanto, do ponto de visto matemático, ter sido a melhor expressão do efeito da produção de MS das raízes.

O comprimento da parte aérea nas três leguminosas apresentou resposta diferenciada para as doses de fósforo (Figura 3). Observa-se resposta quadrática para o trevo-persa, com maior valor na dose zero $(100,96 \mathrm{~cm})$.

No Lotus El Rincón, o melhor resultado do comprimento da parte aérea foi proporcionado pela dose três vezes a recomendação $(90,82$ cm). A máxima eficiência biológica estimada para a adubação fosfatada no comprimento da parte aérea foi constatada pela dosagem 2,69 vezes a recomendada. Para o trevo-subterrâneo, o maior comprimento da parte aérea $(47,62 \mathrm{~cm})$ foi obtido com a aplicação da dose uma vez a recomendada.

Os valores médios de comprimento de raízes das três espécies ficaram entre 70 e $75 \mathrm{~cm}$. No entanto, foi difícil separar as raízes do solo, comprometendo a precisão e aumentando o erro experimental, o que

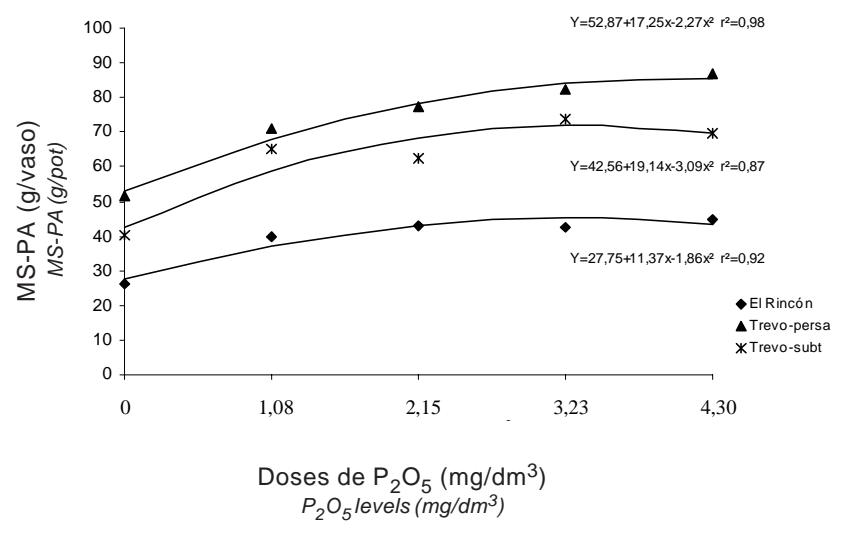

Figura 1 - Produção de matéria seca da parte aérea ( $Y=g / v a s o)$ do Lotus El Rincon, Trevo-persa e Trevo-subterrâneo, em função de doses de fósforo $\left(\mathrm{X}=\mathrm{mg} / \mathrm{dm}^{3}\right.$ de $\left.\mathrm{P}_{2} \mathrm{O}_{5}\right)$.

Figure 1 - Dry matter yield of aerial biomass ( $Y=g / p o t)$ of Lotus El Rincon, Persian clover and Subterraneum clover, according to phosphorus levels $\left(X=m / d^{3}\right.$ of $\mathrm{P}_{2} \mathrm{O}_{5}$ ). pode explicar a ausência de diferença estatística.

Na Figura 4, observa-se a nodulação em resposta às diferentes doses de fósforo e potássio. Nota-se que o escore da nodulação $(3,24)$, na maior dose, para as três espécies com a adubação fosfatada, foi obtido com a dose quatro vezes a recomendada.

Com a adubação potássica, o maior escore $(2,85)$ foi constatado, também, com a dose quatro vezes a recomendação. Esses resultados demonstram a importância da disponibilidade no solo dos nutrientes $\mathrm{P}$ e K, citada por Werner (1984) e Jones et al. (1977), para que possa haver boa nodulação nas plantas leguminosas e conseqüente fixação de nitrogênio.

Na variável eficiência da nodulação, a análise de variância detectou significância $(\mathrm{P}<0,05)$ apenas para o efeito de espécie, entre os fatores estudados. A espécie que apresentou maior eficiência foi o trevosubterrâneo (2,63), seguido do Lotus El Rincón $(2,09)$ e trevo-persa $(1,99)$, que não diferiram entre si (Tabela 1). A não resposta sobre a produção de matéria seca e eficiência de nodulação para K provavelmente seja conseqüência da elevada disponibilidade desse nutriente no solo.

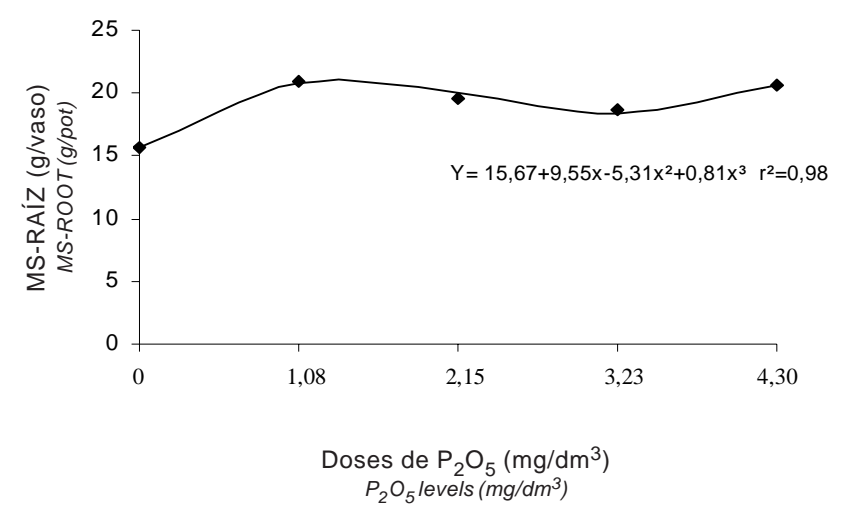

Figura 2 - Produção de matéria seca das raízes ( $Y=g / v a s o)$ das três espécies de leguminosas, em função das doses de fósforo $\left(X=\mathrm{mg} / \mathrm{dm}^{3}\right.$ de $\mathrm{P}_{2} \mathrm{O}_{5}$ ).

Figure 2 - Dry matter yield of roots $(Y=g / p o t)$ of three legumes, according to phosphorus levels $\left(X=m / d^{3}\right.$ of $\left.\mathrm{P}_{2} \mathrm{O}_{5}\right)$. 


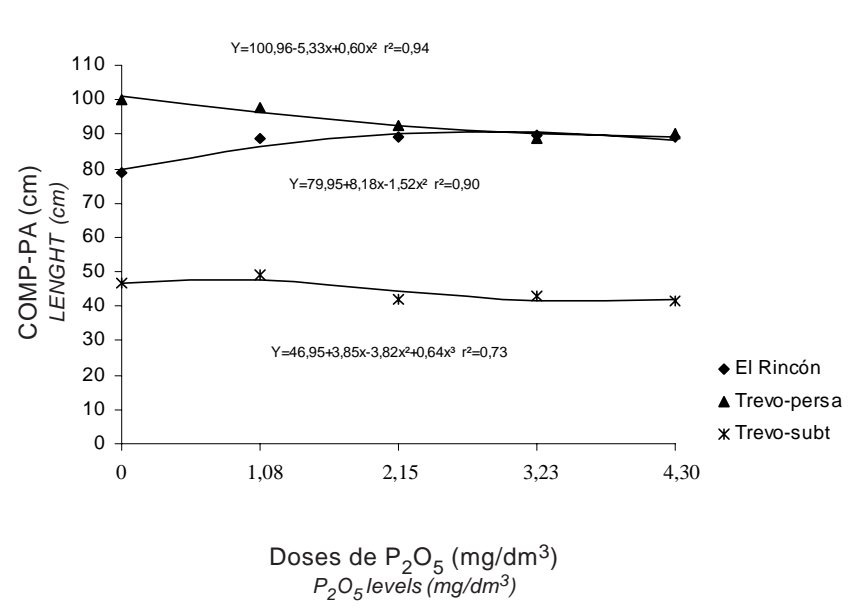

Figura 3 - Comprimento da parte aérea $(\mathrm{Y}=\mathrm{cm}$ de hastes+folha) do Lotus El Rincon, Trevopersa e Trevo-subterrâneo, em função das doses de fósforo $\left(\mathrm{X}=\mathrm{mg} / \mathrm{dm}^{3}\right.$ de $\left.\mathrm{P}_{2} \mathrm{O}_{5}\right)$.

Figure 3 - Length of above ground ( $Y=\mathrm{cm}$ of stem+leaf) of Lotus El Rincon, Persian clover and Subterraneum clover, according to phosphorus levels $\left(X=m / \mathrm{dm}^{3}\right.$ of $\left.\mathrm{P}_{2} \mathrm{O}_{5}\right)$.

\section{Conclusões}

Apenas o fósforo influencia a biomassa da parte aérea, do sistema radicular, a nodulação e o tipo de nódulos em Lotus El Rincon, trevo persa e trevo subterrâneo.

A dose de fósforo que proporciona a máxima produção de MS, nas espécies leguminosas, é $2,15 \mathrm{mg} / \mathrm{dm}^{3}$, enquanto o potássio não influencia a produção de MS das leguminosas estudadas.

O trevo-persa é a espécie que apresenta maior produção de matéria seca.

As leguminosas que apresentam maior número de nódulos e eficiência de nodulação são o trevosubterrâneo e o Lotus El Rincón.

\section{Literatura Citada}

ABRAMIDES, P.L.G. Desempenho de bovinos em pastagens consorciadas. In: SIMPÓSIO SOBRE PRODUÇÃO ANIMAL, 2., 1986, Campinas. Anais... Campinas: 1986, 108p.

BAILEY, J.S.; LAIDLAW, A.S. Growth and development of white clover (Trifolium repens L.) as influenced by $\mathrm{P}$ and K Nutrition. Annals of Botany, v.81, p.783-786, 1988.

BAUER, C.A. Diversificação de culturas em Santa Vitória do Palmar. In: SIMPÓSIO SOBRE ALTERNATIVAS AO SISTEMA TRADICIONAL DE UTILIZAÇÃO DE VÁRZEAS DO RIO GRANDE DO SUL, 1984, Porto Alegre. Anais... Porto Alegre: 1984. p.61-66.

R. Bras. Zootec., v.33, n.6, p.2223-2230, 2004 (Supl. 3)

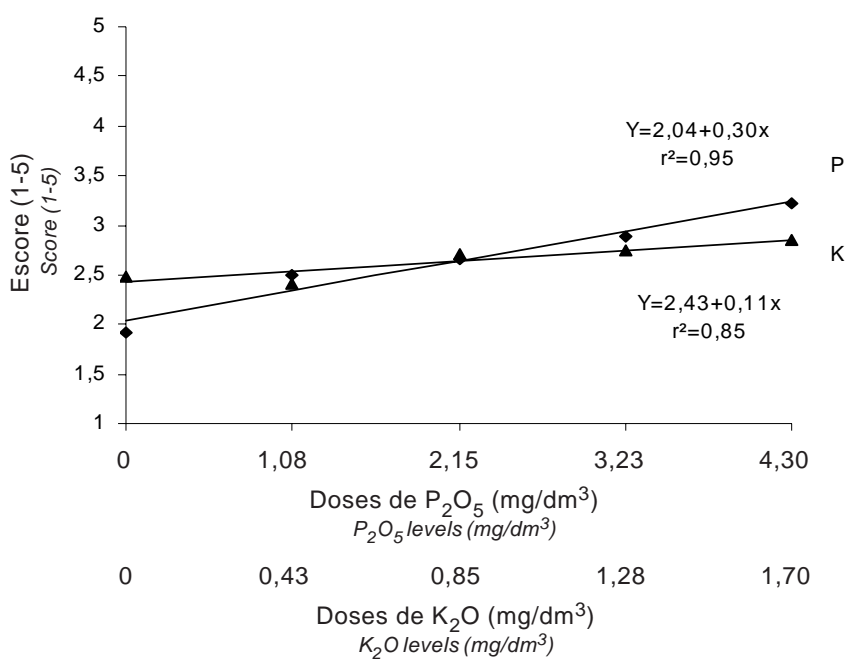

Figura 4 - Número de nódulos (Y=escore 1-5) nas raízes das plantas de Lotus El Rincon, Trevo-persa e Trevo-subterrâneo, em função das doses de fósforo $\left(\mathrm{X}=\mathrm{mg} / \mathrm{dm}^{3}\right.$ de $\left.\mathrm{P}_{2} \mathrm{O}_{5}\right)$ e potássio $\left(\mathrm{X}=\mathrm{mg} / \mathrm{dm}^{3}\right.$ de $\left.\mathrm{K}_{2} \mathrm{O}\right)$.

Figure 4 - Score of nodulatioon ( $Y=$ score 1-5) on roots of plants of Lotus El Rincon, Persian clover and Subterraneum clover, , according to phosphorus levels $\left(X=m / d m^{3}\right.$ of $\left.P_{2} O_{5}\right)$ and potassium levels $\left(X=m / d m^{3}\right.$ of $\left.K_{2} O\right)$.

BRASIL. Ministério da Agricultura. Departamento Nacional de Pesquisa Agropecuária. Divisão de Pesquisas Pedológicas. Levantamento de Reconhecimento dos Solos do Estado do Rio Grande do Sul. Recife, 1973. 431p. (Boletim Técnico, 30).

CARÂMBULA, M.; DURÁN, A. Respuesta del Trifolium subterraneum a diferentes fertilizantes fosfatados en una pradera arenosa sobre areniscos de Tacuarembó. Boletim Técnico da Estação Experimental de Paysandú, n.4, p.8-11, 1964.

COMISSÃO DE FERTILIDADE DO SOLO-RS/SC. Recomendações de adubação e de calagem para os estados do Rio Grande do Sul e Santa Catarina. 3.ed. Passo Fundo, 1994. 224p.

CORREIA, A.A.D. Bioquímica nos solos, nas pastagens e forragens. Fundação Calouste Gulbenkian, 1983. 789p.

CROWDER, L.V.; CHHEDA, H.R. Tropical grassland husbandry. New York. Longman, 1982. 562p.

GOMES, A.S.; SOUZA, R.O.; LERÍPIO, A.A. Produtividade do arroz irrigado em diferentes sistemas de cultivo. In: REUNIÃO DA CULTURA DO ARROZ IRRIGADO, 20., 1993, Pelotas. Anais... Pelotas: EMBRAPA-CPACT, 1993. p.135-137

GUSS, A.; GOMIDE, J.A.; NOVAIS, R.F. Exigências de fósforo para estabelecimento de quatro leguminosas forrageiras em solos com distintas características físicoquímicas. Revista da Sociedade Brasileira de Zootecnia, v.19, p.450-458, 1990.

HONDA, C.S.; HONDA, A.M. Cultura da alfafa. São Paulo: Livroceres, 1990. 245p

JONES, G.D.; LUTZ Jr, J.A.; SMITH, T.J. Effects of phosphorus and potassium on soybean nodules and seed yield. Agronomy Journal, v.69, n.6, p.1003-1006, 1977.

JONES, M.B.; FREITAS, L.M.M. Respostas de quatro leguminosas tropicais a fósforo, potássio e calcário num latossolo vermelho-amarelo de campo cerrado. Pesquisa Agropecuária Brasileira, n.5, p.91-99, 1970. 
KORNELIUS, E. Influência da calagem e de adubação fosfatada na produção de alfafa (Medicago sativa $L$.) em seis solos do Rio Grande do Sul. Porto Alegre: Universidade Federal do Rio Grande do Sul, 1972. 126p. Dissertação (Mestrado) Universidade Federal do Rio Grande do Sul, 1972.

LOPES, J.R.C.; MONKS, P.L. Efeito da calagem e da adubação na produtividade de trevo-persa (Trifolium resupinatum L.). In: REUNIÃO ANUAL DA SOCIEDADE BRASILEIRA DE ZOOTECNIA, 22., 1985, Balneário Camboriú. Anais... Florianópolis: Sociedade Brasileira de Zootecnia, 1985. p.326.

MALAVOLTA, E.; HAAG, H.P.; MELLO, F.A.F. et al. Nutrição mineral e adubação de plantas cultivadas. São Paulo: Pioneira, 1974. 727p.

MARCHEZAN, E.; VIZZOTTO, V.R.; ROCHA, M.G. et al. Produção animal em várzea sistematizada cultivada com forrageiras de estação fria submetidas a diferentes níveis de adubação. Ciência Rural, v.32, n.2, p.303-308, 2002.

MONTEIRO, F.A.; LIMA, S.A.A.; WERNER, J.C. et al. Adubação potássica em leguminosas e em capim-colonião adubado com níveis de nitrogênio ou consorciado com leguminosas. Boletim de Indústria Animal, v.37, n.1, p.127-148, 1980.

MOREIRA, A.; MALAVOLTA, E.; MORAES, L.A. C. Eficiência de fontes e doses de fósforo na alfafa e centrosema cultivadas em Latossolo Amarelo. Pesquisa Agropecuária Brasileira, v.37, n.10, p.1459-1466, 2002.

MORÓN, A.; RISSO, D.F. Phosphorus, sulfur and micronutrients on grassland improvement with white clover (Trifolium repens L.) on basaltic soils in Uruguay. In: INTERNATIONAL GRASSLAND CONGRESS, 2001, São Pedro. Anais... Piracicaba: Fundação de Estudos Agrários Luiz de Queiroz, 2001. p.181-182.

OLIVEIRA, L.I.T. Potencial de produção e qualidade da forragem do campo natural de Planossolo, visando a produção de feno, sob diferentes doses e fracionamento do nitrogênio. Pelotas: Universidade Federal de Pelotas, 1995. 120p. Dissertação (Mestrado) - Universidade Federal de Pelotas, 1995.

POTTER, V.J. Utilização de várzeas na Estância Guatambú. In: SIMPÓSIO SOBRE ALTERNATIVAS AO SISTEMA TRADICIONAL DE UTILIZAÇÃO DAS VÁRZEAS DO RIO GRANDE DO SUL, 1., 1984, Porto Alegre. Trabalhos apresentados... Brasília: PROVÁRZEAS/PROFIR, 1986. p.46-49.
RHYKERD, C.L.; OVERDHAL, C.J. Nutrition and fertilizer use. Alfafa Science and Technology, 1972. 812p.

RISSO, F.D. Efeito de la densidade de siembra y fertilizacion inicial en el comportamiento de tres leguminosas sembradas en cobertura. In: SEMINÁRIO NACIONAL DE CAMPO NATURAL, 2., 1990, Tacuarembó. Anais... Tacuarembó: 1990. p.243-247.

ROCHA, M.G.; RESTLE, J.; FRIZZO, A. et al. Alternativas de utilização da pastagem hibernal para recria de bezerras de corte. Revista Brasileira de Zootecnia, v.32, n.2, p.383392, 2003.

SAMPAIO, N.V. Avaliação de métodos e épocas de inoculação em pós-emergência em trevo-subterrâneo (Trifolium subterraneum L. cv. Clare). Pelotas: Universidade Federal de Pelotas, 1988. 77p. Dissertação (Mestrado) - Universidade Federal de Pelotas, 1988.

SHEARD, R.W.; BRADSHAW, G.J.; MASSEY, D.L. Phosphorus placement for the establishment of alfalfa and bromegrass. Agronomy Journal, v.63, n.6, p.922-927, 1971.

STAMMEL, J.G. Influência da calagem e da adubação na produção de trevo-vermelho em três solos do Rio Grande do Sul. Porto Alegre: Universidade Federal do Rio Grande do Sul, 1968. 89p. Dissertação (Mestrado) - Universidade Federal do Rio Grande do Sul, 1968.

WERNER, J.C. Adubação de pastagens. Nova Odessa: Instituto de Zootecnia, 1984. 49p. (Boletim Técnico, 18)

WERNER, J.C.; MONTEIRO, F.A.; MEIRELLES, N.M.F. Efeito das adubações com fósforo, potássio e molibdênio mais cobre na consorciação de capim-gordura com centrosema. Zootecnia, v.21, n.2, p.109-134, 1983.

ZONTA, E.P.; MACHADO, A.D. SANEST - Sistema de análise estatística para microcomputadores. Pelotas: Universidade Federal de Pelotas, 1984. 75p. 